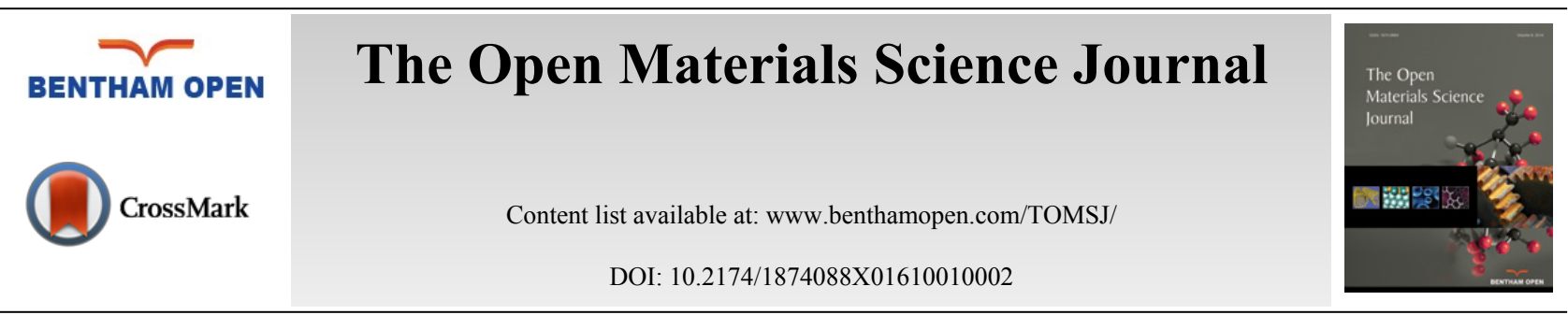

\title{
Study on Thermal Performance of Composites Prepared Using Poly(L-Lactic Acid) and Melamine
}

\author{
Yan-Hua Cai ${ }^{1,2, *}$ and Li-Sha Zhao ${ }^{1,2}$ \\ ${ }^{I}$ Chongqing Key Laboratory of Environmental Materials \& Remediation Technologies, Chongqing University of Arts \\ and Sciences, Yongchuan, Chongqing-402160, P.R. China \\ ${ }^{2}$ School of Materials and Chemical Engineering, Chongqing University of Arts and Sciences, Yongchuan, \\ Chongqing-402160, P.R. China
}

Received: July 27, 2015

Revised: September 18, 2015

Accepted: September 18, 2015

\begin{abstract}
The goal of this work was to study the non isothermal and isothermal crystallization behavior of Poly(L-lactic acid) (PLLA) with melamine (TP) through differential scanning calorimeter and optical depolarizer. The study of the crystallization behavior of PLLA/TP composites indicated that TP could promote the crystallization of PLLA. The half time of overall crystallization of PLLA with $1.5 \mathrm{wt} \% \mathrm{TP}$, compared with the neat PLLA, gave rise to a decrease from $3999.44 \mathrm{~s}$ to the minimum value $228 \mathrm{~s}$ at $100{ }^{\circ} \mathrm{C}$. In addition, the cooling rate also affected significantly the crystallization behavior of PLLA. The melting behavior of PLLA/TP composites exhibited a complicated and different melting process after cooling crystallization, and the increasing of TP content made melt mass flow rate of PLLA firstly decrease, then increases.
\end{abstract}

Keywords: Composites, Crystallization, Fluidity, Melamine, Poly(L-lactic acid).

\section{INTRODUCTION}

In the past ten years, biodegradable polymers exhibited extensive attention due to little environmental pollution. Poly(L-lactic acid) (PLLA) among biodegradable polymer is the most typical bio based and degradable thermoplastic polymer materials, and the scientists in the global also had done a large number of works for developing the novel materials based on PLLA [1 - 3]. For examples, clay is often used to improve the performance of PLLA. Maider et al. reported the use of clay could increase the thermal stability of PLLA/nanoclay nanocomposites, and decreased the degradation rate during processing [4]. Cele et al. [5] also used clay to investigate the effect of nanoclay on optical properties of PLLA/clay films. The morphological results of PLLA/clay films showed surface roughness increased as a function of clay content, and the refractive index, extinction coefficient and absorption of light correlated with the thickness of PLLA/clay films and clay loading, respectively. In addition, to improve the crystallization performance of PLLA, many works were carried out to increase the degree of crystallization of PLLA. The literature [6] highlighted that the presence of talc could increase significantly the degree of crystallization and decrease the crystal size of PLLA in PLLA/PCL/talc ternary systems. Similarly, $\mathrm{ZnO}$ also had good heterogeneous nucleation effect in PLLA matrix, and played a very key role in accelerating the crystallization rate of PLLA [7].

Melamine (TP) with high nitrogen is very common chemical raw materials, and has used in multiple fields such as polymer [8], chemical synthesis [9], flame retardant [10], etc. Furthermore, TP has attracted more and more attention with country's increasing attention to food safety. Besides, because TP has amino, high electron density and rigid structure (See Fig. 1), which results in that the TP still be the most important additive.

Amino of TP easily makes the interaction between PLLA and melamine, moreover, the rigid structure of melamine

\footnotetext{
* Address correspondence to this author at the Chongqing Key Laboratory of Environmental Materials \& Remediation Technologies, Yongchuan, Chongqing-402160, P.R. China; E-mail: caiyh651@aliyun.com
} 
may make the molecular chain of PLLA gather in TP to be regular structure. According to the above two points, in this paper, TP was introduced into PLLA to prepare PLLA/TP composites using common melt blended technology, and the effect of TP on nucleating effect, isothermal crystallization kinetics of PLLA was investigated using DSC, optical depolarizer, etc. The results of this work may exhibit a potential application.<smiles>Nc1nc(N)nc(N)n1</smiles>

Fig. (1). Structure of melamine.

\section{EXPERIMENT}

\subsection{Materials}

Poly(L-lactic acid) (2002D) was purchased from Nature Works LLC (USA). Melamine (TP) was obtained from Huanwei Chemical Reagents Company from Chongqing of China.

\subsection{Preparation of PLLA/TP Composites}

The detailed processing procedure of PLLA/TP composites with different TP content is similar to that of others composites in our earlier works $[11,12]$.

\subsection{Test}

\section{Crystallization Behavior Measurement}

The isothermal crystallization behavior of PLLA/TP composites was performed on a optical depolarizer from $90{ }^{\circ} \mathrm{C}$ to $115^{\circ} \mathrm{C}$. And the non isothermal crystallization and melting behavior at different cooling rate were carried out though differential scanning calorimeter (DSC) Q2000 with $50 \mathrm{ml} / \mathrm{min}$ nitrogen.

\section{Melt Index}

The fluidity of melting PLLA/TP composites was measured by melt index instrument, the measurement temperature was $145^{\circ} \mathrm{C}$, load is $10 \mathrm{Kg}$. And the melt mass flow rate (MFR) was calculated and obtained by averaging over three specimens.

\section{RESULTS AND DISCUSSION}

\subsection{Non Isothermal and Isothermal Crystallization}

Fig. (2) shows the non isothermal crystallization of the neat PLLA and PLLA with 2 wt $\%$ TP (designated here as PLLA $/ 2 \% \mathrm{TP}$ ) at different cooling rate. It is very clear from Fig. (2) that the addition of TP makes the crystallization behavior of PLLA occur to the change, Upon the cooling rate of $1{ }^{\circ} \mathrm{C} / \mathrm{min}, 3{ }^{\circ} \mathrm{C} / \mathrm{min}$ and $5{ }^{\circ} \mathrm{C} / \mathrm{min}$, the non-isothermal crystallization peak of the neat PLLA hardly is observed. However, PLLA $/ 2 \% \mathrm{TP}$ exhibits obvious crystallization peak, what is more, the crystallization peaks at all cooling rates are very sharp, these results indicate that TP could promote the crystallization of PLLA. Meantime, it is a fact that the crystallization peak of PLLA/2\%TP widens and shifts to low temperature with the increasing of cooling rate, the possible reason is that the increasing of cooling rate makes the ability of PLLA molecular chain arrangement weaken, resulting in decreasing of crystallization ability of PLLA. In addition, it is also observed that the crystallization peak nearly moves at cooling rate of $3{ }^{\circ} \mathrm{C} / \mathrm{min}$ and $5{ }^{\circ} \mathrm{C} / \mathrm{min}$, exhibiting a complicated crystallization procedure. In a word, these results show that cooling rate is very important factor for crystallization of PLLA.

Isothermal crystallization performance is also very interesting research content to deeply know the role of the additive in polymer matrix. The effect of crystallization temperature and TP content on half time of overall crystallization $t_{1 / 2}$ of PLLA was showed in Fig. (3). As seen in Fig. (3), the addition of TP makes the $t_{1 / 2}$ extremely decrease. The $t_{1 / 2}$ of the neat PLLA decreases with the increasing of isothermal crystallization temperature in the range 
from $95{ }^{\circ} \mathrm{C}$ to $115{ }^{\circ} \mathrm{C}$. However, the $t_{1 / 2}$ of PLLA/TP composites exhibits the regular change with crystallization temperature, that is to say, the $t_{1 / 2}$ of PLLA/TP composites firstly decreases, then increases, and the $t_{1 / 2}$ exhibits the minimum value at $100^{\circ} \mathrm{C}$. Meantime, TP content also affects he $t_{1 / 2}$ of PLLA. In general, the $t_{1 / 2}$ of PLLA/TP decreases with increasing of TP content. Compared to the neat PLLA, 1.5\%TP makes the $t_{1 / 2}$ of PLLA decrease from $3999.44 \mathrm{~s}$ to $228 \mathrm{~s}$.

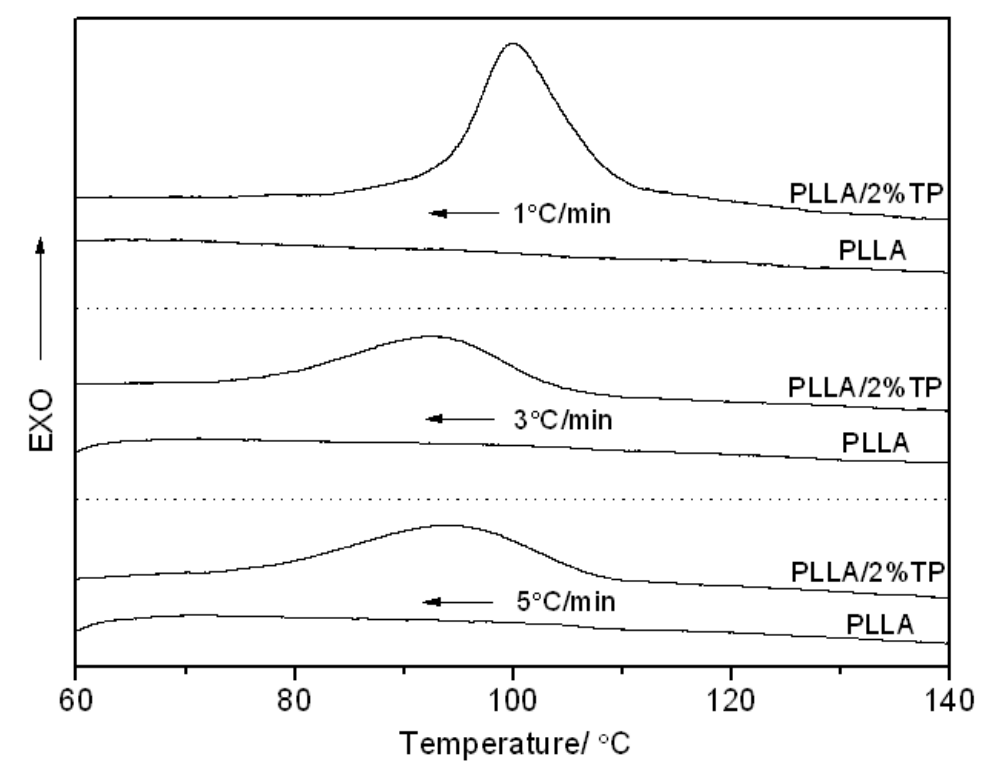

Fig. (2). Non isothermal crystallization of PLLA and PLLA/2\%TP at different cooling rate.

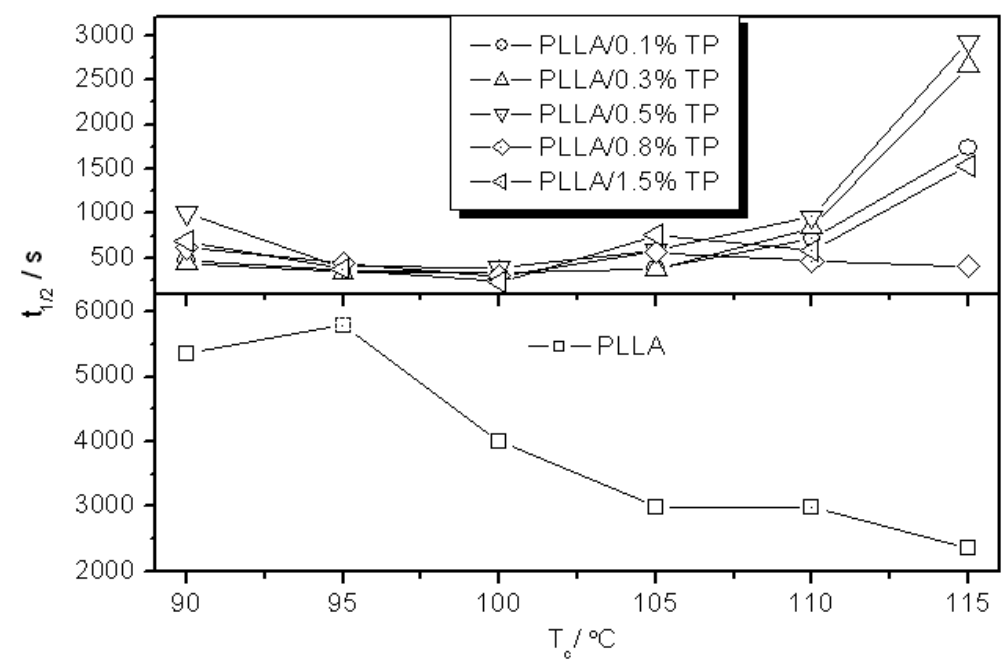

Fig. (3). Effect of crystallization temperature and TP content on $t_{1 / 2}$ of PLLA.

In addition, the kinetics of the isothermal crystallization of PLLA/TP composites were also described through Avrami equation as our previous work [13]. Fig. (4) shows the avrami plots of PLLA/TP sample, the relationship of log $[-\ln (1-\mathrm{Xt})]$ versus logt is linear, and the linear relationship is better, which indicates that Avrami equation can be used to accurately describes the kinetics of crystallization of PLLA/TP.

\subsection{Melting Behavior and Fluidity}

Fig. (5) shows the melting behavior of PLLA/TP composites at heating rate of $10{ }^{\circ} \mathrm{C} / \mathrm{min}$ after cooling crystallization from melt at cooling rate of $1{ }^{\circ} \mathrm{C} / \mathrm{min}$. There exist double melting peaks during melting process of PLLA/TP samples, the phenomenon of double-melting peaks were reported continually during melting process of polymer materials in a large number of literature [14], and a increasing of TP content makes the low temperature 
melting peak and high temperature melting peak shift to lower temperature, and the melting endotherms with doublemelting peak gradually change to the single endotherms, which exhibits a very strange phenomenon. As the aforementioned crystallization results, the crystallization ability of PLLA with high loading TP is better than that with low loading TP. Thus, the low-temperature melting peak of PLLA with high loading TP would become sharper. However, the low temperature melting peak of PLLA/TP composites weakens with the increasing of TP content. What is more, the high temperature melting peak firstly strengthens, then weakens with increasing of TP, which indicates that high loading TP makes the forming crystal exhibit a more difference after non-isothermal crystallization process and second heating process. The strange melting behavior may result from the effective dispersion of TP in PLLA matrix, on the other hand, the melting process of PLLA/TP composites is very complicated.
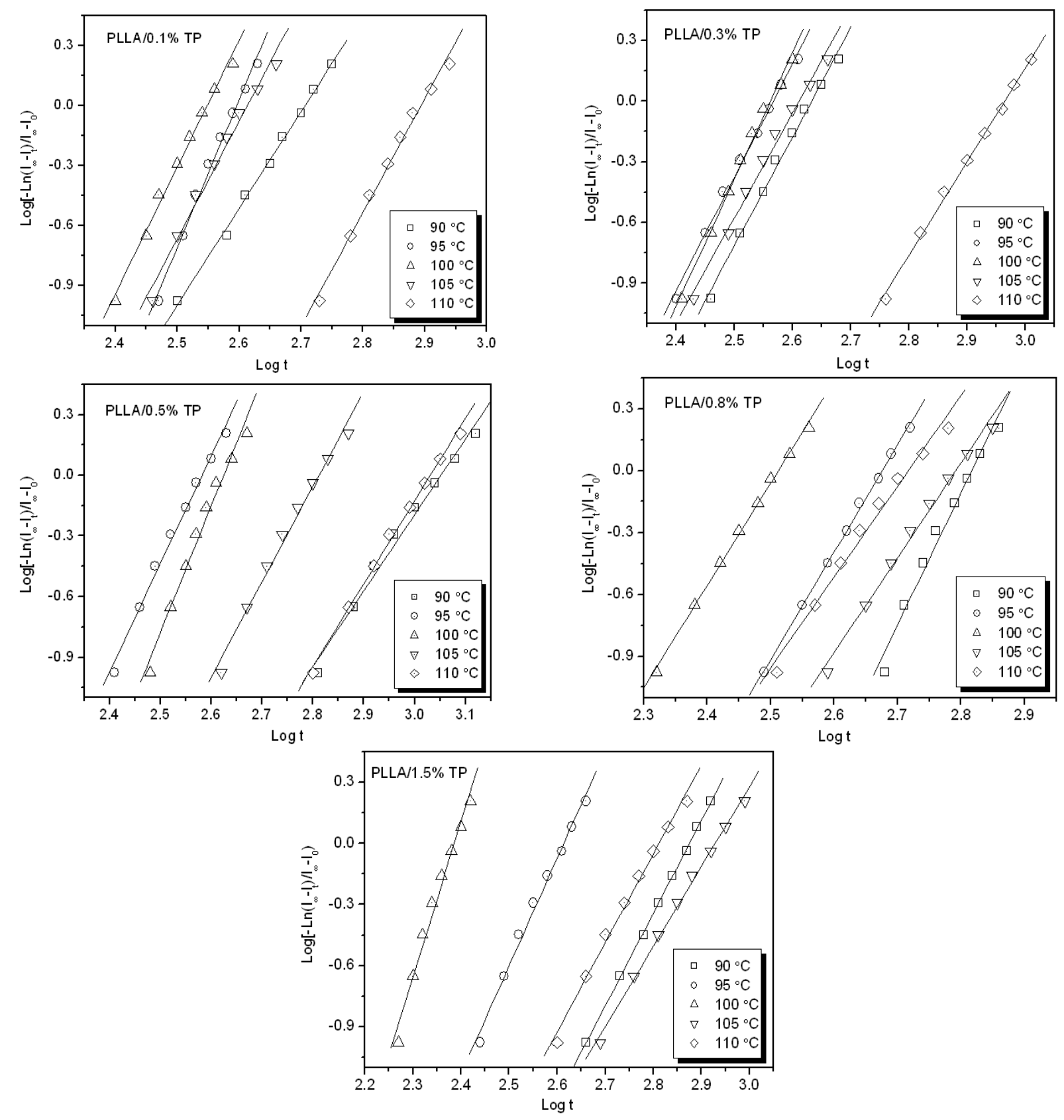

Fig. (4). Avrami plots for PLLA/TP at different temperature.

The fluidity is very important factor for processing, and the fluidity of PLLA/TP from Fig. (6) shows that the melt mass flow rate (MFR) of PLLA firstly slightly decreases, then greatly increases with TP increasing, resulting from that 
the addition of TP may decrease the interaction between PLLA molecular chain.

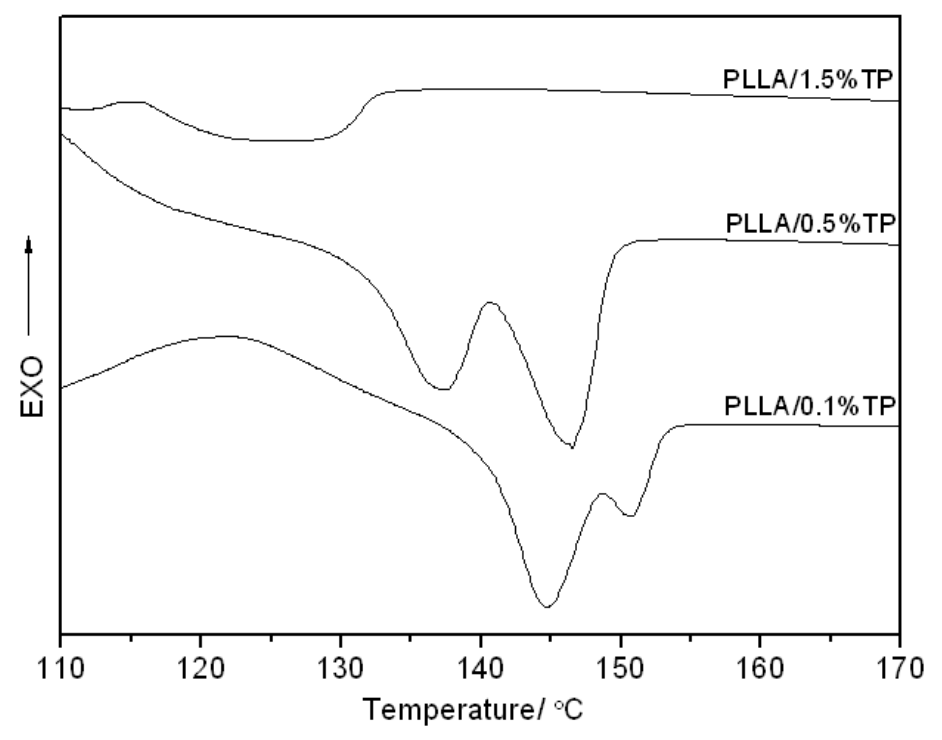

Fig. (5). Melting behavior of PLLA/TP at the heating rate of $10^{\circ} \mathrm{C} / \mathrm{min}$ after cooling crystallization.

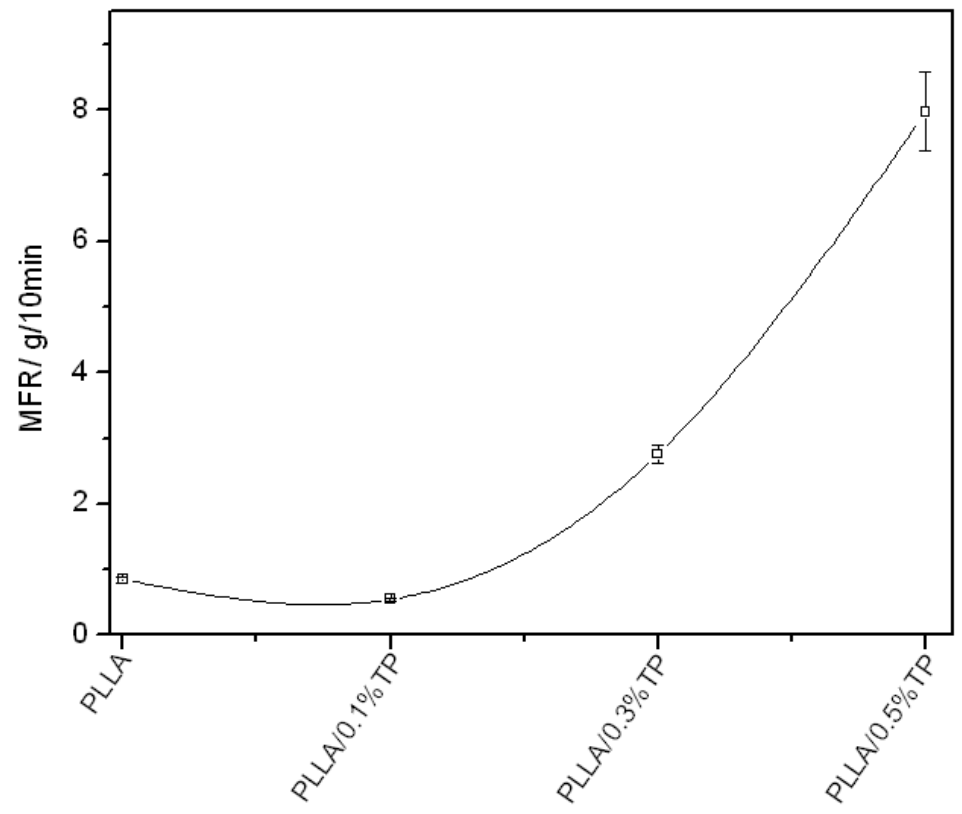

Fig. (6). Effect of TP on melt mass flow rate of PLLA.

\section{CONCLUSION}

The PLLA/TP composites were fabricated using rheometer, and The observation from DSC and optical depolarizer measurements showed that TP could serve as accelerator for the crystallization of PLLA, but the crystallization of PLLA and PLLA/TP composites was also affected by the cooling rate. Similarly, the TP content and crystallization temperature affected significantly the isothermal crystallization process, and upon the 1.5\% TP, PLLA had the minimumt $_{1 / 2}$ at $100{ }^{\circ} \mathrm{C}$. the cooling rate also affected significantly the crystallization behavior of PLLA. In addition, the addition of TP also resulted in the a complicated and different melting process after cooling crystallization, and the MFR of PLLA firstly decrease, then increases with the increasing of TP content. 


\section{CONFLICT OF INTEREST}

The authors confirm that this article content has no conflict of interest.

\section{ACKNOWLEDGEMENTS}

This work was supported by China Postdoctoral Science Foundation (Project No. 2013M531937), Natural Science Foundation of Chongqing Municipal Science and Technology Commission (Project No. cstc2015jcyjBX0123) and Chongqing University of Arts and Sciences (Project No. R2013CH11).

\section{REFERENCES}

[1] Harris AM, Lee EC. Improving mechanical performance of injection molded PLA by controlling crystallinity. J Appl Polym Sci 2008; 107(4): 2246-55. [http://dx.doi.org/10.1002/app.27261]

[2] Ogata N, Jimenez G, Kawai H, Ogihara T. Structure and thermal/ mechanical properties of poly(1-lactide)-clay blend. J Polym Sci, B, Polym Phys 1997; 35(2): 389-96. [http://dx.doi.org/10.1002/(SICI)1099-0488(19970130)35:2<389::AID-POLB14>3.0.CO;2-E]

[3] Li XX, Yin JB, Yu ZY, et al. Isothermal crystallization behavior of poly(L-lactic acid)/organo-montmorillonite nanocomposites. Polym Compos 2009; 30(9): 1338-44.

[http://dx.doi.org/10.1002/pc.20721]

[4] Iturrondobeitia M, Okariz A, Guraya T, Zaldua AM, Ibarretxe J. Influence of the processing parameters and composition on the thermal stability of PLA/Nanoclay bio-nanocomposites. J Appl Polym Sci 2014; 131: 40747. [http://dx.doi.org/10.1002/app.40747]

[5] Cele HM, Ojijo V, Chen H, et al. Effect of nanoclay on optical properties of PLA/clay composite films. Polym Test 2014; 36: 24-31. [http://dx.doi.org/10.1016/j.polymertesting.2014.03.010]

[6] Russo P, Acierno D, Vignali A, Lavorgna M. Poly(lactic acid)-based systems filled with talc microparticles: thermal, structural, and morphological issues. Polym Compos 2014; 35: 1093-103.

[7] Zhen WJ, Sun JL. Properties, structure and crystallization of poly lactic acid/zine oxide pillared organic saponite nanocomposites. Polymer (Korea) 2014; 38(3): 299-306 [http://dx.doi.org/10.7317/pk.2014.38.3.299]

[8] Liu D, Cai GP, Wang J, et al. Thermal and falmmbility performance of polypropylene composiyes containing melamine and melamine phosphate-modified $\alpha$-type zirconium phosphates. J Appl Polym Sci 2014; 131(6): 82-6. [http://dx.doi.org/10.1002/app.40254]

[9] Han SG, Wu YF, Lu XN. 13C-NMR Spectromrtry study on chemistry structures and reaction of melamine modified Urea-formaldehyde resin. J nanjing for univ (Natural sciences edition) 2007; 31: 40254.

[10] Li D, Hu JP, Qin Y, Sun CM, Wang XY. Combustion behavior and pyrolysis of epoxy resins blended with caged bicyclic dimelamine phosphate. J Funct Poly 2007; 19-20(1): 81-6.

[11] Cai YH, Yin JB, Fan YQ, Yan SF, Chen XS. Crystallization behavior of biodegradable poly(L-lactic acid) filled with a powerful nucleating agent-N, N'-Bis(benzoyl) suberic acid dihydrazide. J Appl Polym Sci 2011; 121(3): 1408-16. [http://dx.doi.org/10.1002/app.33633]

[12] Cai YH. Isothermal crystallization behavior of poly (L-lactic acid)/surface-grafted silica nanocomposites. Appl Mech Mater 2013; 268-270: $37-40$. [http://dx.doi.org/10.4028/www.scientific.net/AMM.268-270.37]

[13] Cai YH, Miao YW, Wang ZY. Isothermal crystallization behavior of poly(L-lactic acid)/organo-montmorillonite composites. Asian J Chem 2014; 26(4): 1237-40.

[14] Wang YM, Mano JF. Influence of melting conditions on the thermal behavior of poly(L-lactic acid). Eur Polym J 2005; 41 (10): 2335-42. [http://dx.doi.org/10.1016/j.eurpolymj.2005.04.030]

(C) Cai and Zhao; Licensee Bentham Open.

This is an open access article licensed under the terms of the Creative Commons Attribution-Non-Commercial 4.0 International Public License (CC BY-NC 4.0) (https://creativecommons.org/licenses/by-nc/4.0/legalcode), which permits unrestricted, non-commercial use, distribution and reproduction in any medium, provided the work is properly cited. 